ARTIGOS

\title{
AS COMPETÊNCIAS GERENCIAIS DO PAPEL DE FACILITADOR NA ATUAÇÃO DO GESTOR SECRETARIAL
}

\section{RESUMO}

O secretário executivo contribui diretamente para o alcance dos resultados organizacionais. Exerce diversos papéis e, para tanto, precisa desenvolver permanentemente as competências gerenciais necessárias à sua atuação. A presente pesquisa aborda o papel de

Conceição de Maria Pinheiro Barros conceicaompb@yahoo.com.br Doutorado em Educação. Mestrado em Politicas Públicas e Gestão da Educação Superior. Bacharel em Secretariado Executivo. Especialização em Comércio Exterior. Professora Adjunta da Universidade Federal do Ceará (UFC). Coordenadora do Curso de Secretariado Executivo da UFC. Coordenadora do Núcleo de Estudos e Pesquisas em Secretariado Executivo (NEPES) da Universidade Federal do Ceará (UFC). Fortaleza - CE$B R$.

Joelma Soares da Silva joelma.soares@ufc.br Doutoranda e mestre em Administração na Universidade Estadual do Ceará (UECE). Professora assistente do Departamento de Administração da Universidade Federal do Ceará. Coordenadora adjunta do Núcleo de Estudos e Pesquisas em Secretariado Executivo (NEPES/ $U F C)$. Fortaleza - CE-BR..

Túlio Feitosa Paiva tuliofeitosa@yahoo.com.br Bacharel em Secretariado Executivo pela Universidade Federal do Ceará. Sócioproprietário na empresa Fluness For Men. Fortaleza - CE-BR. facilitador exercido pelos secretários executivos fundamentando-se em Quinn et al. (2003) ao considerarem a influência exercida pelo gestor por meio das competências gerenciais: construção de equipes, processo decisório participativo e administração de conflitos. Este trabalho tem como objetivo investigar as competências gerenciais do papel de facilitador na atuação do gestor secretarial, na visão de profissionais. Para tanto, foi realizada uma pesquisa quantitativo-qualitativa e descritiva, tendo como técnica de coleta de dados a aplicação de um questionário com 100 estudantes e profissionais atuantes em Secretariado Executivo, no Brasil. A análise dos dados revelou que o papel de facilitador organizacional está presente na atuação do secretário como gestor, contribuindo ativamente para o equilíbrio das organizações contemporâneas.

Palavras-chave: Competências gerenciais. Papel Gerencial de Facilitador. Gestão Secretarial.

\section{INTRODUÇ̃̃̃O}

Estudos realizados sobre gestão secretarial (BECKER; CEOLIN, 2010; SILVA; BARROS; BARBOSA, 2012; BARROS et al., 2013) apontam para uma conceituação cada vez mais peculiar ao secretário executivo. Entre as áreas de atuação deste profissional, destacam-se: assessoria, consultoria, empreendedorismo, cooperativa secretarial e gestão (PAES et al., 2015; SANTOS; MORETTO, 2011) no âmbito da esfera pública e privada. Na esfera pública, estudos ressaltam os desafios de sua atuação em Instituições Federais de Ensino Superior (IFES) (LEAL; MORAES, 2017; CUSTÓDIO; FERREIRA; SILVA, 2008). No que tange à esfera privada, percebe-se "a evolução da profissão de secretariado executivo no contexto da dinâmica produtiva brasileira e do mercado de trabalho em geral." (SANTOS; MORETTO, 2011, p. 21). Para atuar como gestor, o secretário executivo precisa desen- 
volver habilidades e competências de gestão, a fim de que exerça as funções que lhe são exigidas no mundo dos negócios.

Esta pesquisa aborda o papel de facilitador organizacional na atuação do gestor secretarial. De acordo com Portela e Schumacher (2009), como agente facilitador, a atuação do secretário executivo se revela nas relações que administra, as quais demandam a percepção do ambiente, das pessoas e dos códigos, seu equilíbrio emocional, a flexibilidade e a filosofia da organização. É nesse contexto que se encontra o objeto de pesquisa deste estudo: as competências gerenciais desenvolvidas pelo gestor secretarial no papel de facilitador.

Tem como principal fundamentação teórica, as proposições de Quinn et al. (2003), ao refletirem que as pessoas estão cada vez mais destinadas a lidar com grupos e equipes e que o agente facilitador é o responsável por incentivar o esforço criativo, gerar coesão e moral e administrar os atritos interpessoais. Assim, emerge a questão norteadora desta investigação: como ocorre a atuação do secretário executivo como facilitador no âmbito organizacional? Este trabalho tem como objetivo investigar as competências gerenciais do papel de facilitador na atuação do gestor secretarial, na visão dos profissionais.

O secretário executivo tem conquistado espaços nas organizações contribuindo para a gestão organizacional e superando uma atuação meramente técnica. Tal contribuição ocorre, entre outros, por meio de atividades que envolvem funções e competências administrativas no âmbito das atividades secretariais. Nessa perspectiva, destacam-se estudos acerca das competências gerenciais necessárias ao gestor secretarial (BARROS; SILVA; FERREIRA, 2015; BARROS et al., 2013) fundamentando-se nos papéis gerenciais propostos por Quinn et al. (2003). As investigações sobre essa temática, porém, necessitam de aprofundamentos relativos a cada um dos papéis de forma que ofereçam subsídios teóricos e empíricos que possibilitem a compreensão de como o secretário executivo colabora efetivamente para a gestão nas organizações. A relevância desta pesquisa reside no fato de que ainda existem lacunas acerca do conceito de gestão secretarial, como afirmam Silva, Barros e Cruz (2016, p. 73): "A Gestão Secretarial é um construto em desenvolvimento, e, embora se tenha popularizado e até mesmo se institucionalizado como conteúdo específico, carece de estudos." Considera-se que esta pesquisa pode contribuir para o avanço dos conhecimentos sobre a gestão secretarial, refletindo positivamente no crescimento da produção do conhecimento da área e servindo de fonte aos profissionais, secretários executivos e discentes que desejam ampliar seu conhecimento acerca do tema.

Para o alcance dos objetivos propostos, foi realizada uma pesquisa quantitativa-qualitativa e descritiva. O universo desta pesquisa constituiu-se de estudantes e profissionais atuantes em Secretariado Executivo, no Brasil. A amostra foi composta por 100 secretários executivos que atuam nos diversos setores organizacionais. $\mathrm{O}$ instrumento de pesquisa utilizado para a coleta de informações foi o questionário. Para a análise dos dados foi utilizada a estatística descritiva e interpretação à luz da teoria estudada, por meio da análise de conteúdo.

O artigo está organizado em cinco seções. A primeira seção é constituída pela introdução do trabalho. Na segunda seção, discute-se a gestão secretarial e as competências do secretário executivo como facilitador organizacional. A terceira seção descreve o percurso metodológico da pesquisa. Na quarta seção são realizadas a apresentação e a análise das informações; a quinta seção expõe as considerações finais.

\section{COMPETÊNCIAS GERENCIAIS DO SECRETÁRIO EXECUTIVO COMO FACILITADOR}

As organizações contemporâneas - cada vez mais inconstantes e vulneráveis às mudanças ambientais, bem como pressionadas pela competitividade acirrada - precisam ser geridas por profissionais altamente capacitados. Ressalta-se o papel do gerente/gestor que se faz 
imprescindível ao sucesso das empresas, partindo do pressuposto de que este profissional possui as habilidades e as competências necessárias para o alto desempenho organizacional, a fim de que garanta não somente a sobrevivência, mas a ascensão dos negócios. Com base nisso e na amplitude e complexidade do tema, torna-se imperativo o estudo sobre as competências gerenciais.

\subsection{ESTUDOS ACERCA DAS COMPE- TÊNCIAS GERENCIAIS}

Na compreensão de Ferreira (2001, p. 374), gestão pode ser definida como o "ato ou efeito de gerir." Gerir, por sua vez, é ter gerência sobre algo, administrar negócios, recursos e pessoas. Quinn et al. (2003) afirmam que a gestão é realizada nas organizações por indivíduos que possuem conhecimentos técnicos, espírito de liderança e visão sistêmica da empresa, com a finalidade de possibilitar o funcionamento de uma área administrativa. A função de gestão exige o desenvolvimento de planejamento, organização, liderança, controle e tomada de decisões.

De acordo com Maximiano (2011), qualquer indivíduo que administre um conjunto de recursos é administrador, gerente ou gestor. Nas organizações, os administradores ou gerentes possuem autoridade e são responsáveis pelo desempenho de outros indivíduos, que formam uma equipe para o alcance dos objetivos organizacionais.

Portanto, faz-se necessário o desenvolvimento de competências gerenciais que viabilizem a tomada de decisão e a utilização de recursos para o alcance dos resultados. Entende-se por gerente, o profissional que possui autoridade e responsabilidade para planejar, organizar, dirigir e controlar processos, recursos e pessoas na busca por resultados empresariais. A fim de que cumpra com eficiência e eficácia todas as suas responsabilidades, o gerente deve desenvolver algumas competências necessárias à sua atuação.

Competência pode ser entendida, de acordo com Fleury e Fleury (2000), como a qualificação de um indivíduo para realizar determinada atividade com eficiência. É um conjunto de conhecimentos, habilidades e atitudes que garantem ao indivíduo alto desempenho na realização de algo. Para Quinn et al. (2003), as competências gerenciais correspondem às capacidades que os gerentes devem adquirir para transpor os desafios organizacionais. Maximiano (2011, p. 19), por sua vez, complementa: "as competências desenvolvem-se por meio de experiência profissional, educação formal e informal e convivência familiar e social."

Na compreensão de Mintzberg (1973), papel gerencial é um conjunto de comportamentos que pertencem a uma função ou posição. $\mathrm{O}$ autor teoriza que o gerente possui três papéis básicos em uma organização: informacional, interpessoal e decisória. As competências essenciais para o bom desempenho do gerente nos papéis citados, segundo Mintzberg (1973), agrupam-se em quatro categorias principais: intelectuais, interpessoais, técnicas e intrapessoais, as quais são divididas em habilidades específicas. O desenvolvimento permanente dessas habilidades confere ao gerente as competências essenciais à sua atuação profissional: competências intelectuais, competências interpessoais, competências técnicas e competências intrapessoais.

Na visão de Quinn et al. (2003), existem oito papéis que o gestor deve exercer no âmbito de uma organização, classificados em quatro modelos: modelo das metas racionais, dos processos internos, das relações humanas e dos sistemas abertos. De acordo com os modelos apresentados por Quinn et al. (2003), os oito papéis do líder nas organizações são: diretor, produtor, monitor, coordenador, facilitador, mentor, inovador e negociador. Para que o gerente assuma esses papéis, deve desenvolver competências específicas.

A gestão é o ato de planejar, organizar, dirigir e controlar pessoas e recursos. Para tanto, faz-se necessária a atuação do gerente, o qual é responsável por tais funções e possui os papeis de diretor, produtor, monitor, coordenador, facilitador, mentor, inovador e negociador, 
no âmbito organizacional. Esses papéis somente são exercidos de maneira produtiva quando o gerente desenvolve as competências intelectuais, interpessoais, técnicas e intrapessoais, necessárias à plena atuação deste profissional.

\subsection{AS COMPETÊNCIAS GERENCIAIS NA ATUAÇÃO DO GESTOR SE- CRETARIAL}

O perfil do secretário executivo evolui continuamente e, em contraste com a antiga realidade da profissão, hoje, este profissional - atuando ao lado do poder decisório das organizações - precisa trabalhar permanentemente para o alcance de resultados (VAZ, 2013).

A complexidade organizacional e profissional descentralizou muitas responsabilidades e funções dos gestores das empresas, os quais passaram a ter necessidade de delegar com mais frequência algumas atribuições da gestão empresarial. O secretário executivo elevou seu nível de atuação nas organizações contemporâneas, assumindo maiores responsabilidades, utilizando cada vez mais seu poder intelectual e conquistando maior participação ativa nos processos decisórios das empresas.

A profissão de Secretariado Executivo evoluiu significativamente em relação aos aspectos de gestão, no entanto, o conceito da gestão secretarial ainda não se solidificou, em virtude da complexidade do tema. Tal obscuridade refere-se ao fato de tratar-se de uma área que possui múltiplos aspectos relacionados à multidisciplinaridade e interdisciplinaridade com outras áreas de conhecimento, como a Administração, por exemplo, em uma relação de interdependência que necessita de melhor compreensão.

De acordo com Silva, Barros e Barbosa (2012), as pesquisas científicas no Secretariado Executivo caminham para um embasamento teórico da gestão secretarial cada vez mais fundamentado. A elaboração do conhecimento teórico não se ampara por um pensamento fundamentado na lógica linear (BICUDO, 2011); a área secretarial se sustenta em um raciocínio sinuoso por meio da multidisciplinaridade e interdisci- plinaridade, visto que "[...] não há um corpo teórico-metodológico bem definido para a área. Em outras palavras, não há teoria suficiente consolidada, nem um método de investigação próprio, com princípios delineadores." (NASCIMENTO, 2012, p. 109). A criação de uma teoria se faz necessária para a evolução da profissão, mas também para que o secretário executivo tenha direcionamento quanto ao que é necessário à sua contribuição para o alcance dos resultados nas organizações contemporâneas.

Estudos acerca da atuação do secretário como gestor têm focalizado entre outros aspectos, as competências gerenciais a serem desenvolvidas em sua atuação. Segundo Barros et al. (2013, p. 35), "com a transformação e o reconhecimento, o profissional antigo dá lugar a um profissional com conhecimentos ecléticos, tanto de estrutura quanto de comportamento organizacional, os quais são as bases da gestão secretarial." Para tanto, fez-se necessário que o secretário executivo desenvolvesse competências necessárias à sua atuação como gestor. A gestão secretarial requer o desenvolvimento de competências gerenciais.

Sobre este aspecto, Barros, Braga e Silva (2011) afirmam que as competências gerenciais do secretário executivo englobam o pensamento estratégico; a capacidade de identificar oportunidade de crescimento, inovar e elaborar objetivos na organização; e estão relacionadas à nova postura que esse profissional assumiu nos últimos anos. Na percepção de Lima e Cantarotti (2010), as competências secretariais se referem às negociações; ao gerenciamento de informações; às funções gerenciais como planejamento, organização, controle e direção; à gestão secretarial e à comunicação.

Com relação às atividades gerenciais na atuação do secretário executivo, Barros et al. (2013) destacam: participação na elaboração do planejamento da organização, organização de métodos e processos de trabalho, organização da realização dos trabalhos a serem desenvolvidos na área secretarial, distribuição de atividades dos funcionários, supervisão das atividades de funcionários, liderança, avaliação 
do alcance de metas e objetivos, acompanhamento de planejamento. A gestão secretarial, embora não possua ainda conceitos estabelecidos e abrangentes, é uma área que cresce proporcionalmente à evolução da atuação dos secretários executivos nas organizações.

No âmbito da gestão secretarial, o profissional deve atuar como agente facilitador um dos papeis gerenciais citados por Quinn et al. (2003) - e, para tanto, precisa desenvolver as competências específicas deste papel e saber qual a melhor maneira de contribuir para o alcance de resultados organizacionais, como facilitador. De acordo com Rodrigues (2004, p. 3), o secretário executivo, sobretudo no papel de gestor, é "um agente transformador de insumos para a obtenção dos resultados esperados pelos clientes." D'elia, Amorim e Sita (2013) afirmam que as atividades secretariais são definidas de maneira estratégica e mensuradas por meio de métricas de gestão.

Nesta realidade, ressalta-se a atuação do secretário como facilitador para o alcance dos objetivos organizacionais. Atuando ao lado do poder decisório, o secretário executivo deve ter visão global da empresa, mesclar competências técnicas e comportamentais, exercitar habilidades de relacionamento e administração de conflitos, trabalhar com foco e acompanhamento de objetivos e metas e, principalmente, aprimorar suas habilidades de comunicação, a fim de que atue como agente facilitador - além da atuação como assessor, gestor e empreendedor - função que as organizações contemporâneas também exigem do secretário executivo (PORTELA; SCHUMACHER, 2009).

Como agente facilitador, a atuação do secretário se revela nas relações que administra, as quais demandam a sua percepção do ambiente, das pessoas e dos códigos, o seu equilíbrio emocional, a sua flexibilidade e a filosofia da organização. Portanto, a atuação deste profissional como agente facilitador tornou-se imprescindível aos processos corporativos.

O secretário executivo deve ser um agente de mudanças priorizando o aprendizado, quanto às constantes mudanças empresariais, uma vez que deve ser o primeiro funcionário da organização a assimilar e a aceitar qualquer mudança provinda dos níveis decisórios, para que atue como multiplicador da conscientização dos benefícios que tais mudanças proporcionarão à empresa. O profissional deve ser agente facilitador no processo de comunicação corporativa. Segundo Portela e Schumacher (2009), esse profissional deve minimizar os ruídos da comunicação com clientes internos e externos para que os processos decisórios e os resultados empresariais não sofram impactos negativos.

Para tanto, é indispensável que esse profissional desenvolva também, a cada dia, a sua plena comunicação intrapessoal e interpessoal, que "se referem, respectivamente, às capacidades para fazermos importantes distinções sobre nós mesmos e fazer distinções sobre nossas relações com outras pessoas" (D'ELIA; AMORIM; SITA, 2013, p. 237), uma vez que, para o sucesso na sua carreira, o secretário executivo necessita manter boas relações com as diversas pessoas que se comunicam com ele, todos os dias.

Outra habilidade necessária à atuação do secretário executivo é a de liderança. Gassenferth, Machado e Krause (2012) salientam dois modelos de liderança requeridas dos profissionais pelas organizações: a liderança situacional e a liderança transformacional. O primeiro se baseia nas variáveis "comportamento do líder", e "maturidade dos subordinados". O segundo de liderança - transformacional - se preocupa em aperfeiçoar os liderados, de modo a transformar as suas visões sobre a empresa e o trabalho.

Sendo líder, o secretário executivo precisa trabalhar em equipe de maneira produtiva. De acordo com Rodrigues et al. (2013), uma das competências mais necessárias a um bom profissional de Secretariado Executivo é saber trabalhar em equipe. Além de ajudar no desenvolvimento das atividades, o trabalho conjunto ajuda a aprimorar o convívio social no âmbito da empresa, o que facilita as relações interpessoais desse profissional. No que se refere às competências gerenciais do secretário executivo como facilitador, Barros et al. (2013, p. 40) afirmam que: "Ao atuar como facilitador, os 
secretários investigados apontaram como principal competência a construção de equipes (realização de atividades em equipe contribuindo para a organização das atividades."

As tomadas de decisões pelo secretário executivo acontecem a todo instante, em virtude dos muitos acontecimentos no cotidiano organizacional. Tais mudanças geram, muitas vezes, desgaste nas pessoas envolvidas e, consequentemente, conflitos interpessoais, demandando mais uma competência do profissional secretário: a administração de conflitos.

O perfil desse profissional evolui continuamente e, diferentemente do secretário que possuía o papel apenas de assessor executivo, o gestor secretarial ganha espaço no mercado de trabalho e nas organizações contemporâneas, bem como adquire cada vez mais competências gerenciais necessárias ao seu desenvolvimento.

\section{PROCEDIMENTOS METODOLÓ- GICOS}

Para o alcance dos objetivos propostos, foi desenvolvida uma pesquisa quantitativa-qualitativa considerando-se que "o conjunto de dados quantitativos e qualitativos, porém, não se opõem. Ao contrário, se complementam, pois a realidade abrangida por eles interage dinamicamente, excluindo qualquer dicotomia." (MINAYO, 2001, p. 22).

Essa investigação é classificada como quantitativa por utilizar a quantificação para a coleta de dados e para o seu tratamento por meio de técnica estatística (RICHARDSON, 1999). Classifica-se como qualitativa por traduzir e expressar o sentido dos fenômenos do mundo social, reduzindo a distância entre indicador e indicado, teoria e dados, contexto e ação (NEVES, 1996).

Possui, ainda, caráter descritivo visto que os fatos são observados, registrados, analisados, classificados e interpretados sem a interferência do pesquisador. Neste tipo de pesquisa são utilizadas técnicas padronizadas de coleta de dados, como, por exemplo, o questionário (RODRIGUES, 2007).
Segundo Rodrigues (2007, p. 70), "população ou universo, no sentido geral, é um conjunto de elementos com pelo menos uma característica comum. Essa característica deve delimitar, inequivocamente, quais elementos pertencem ou não à população", enquanto amostra é o subconjunto finito dessa população. O Universo e a população desta pesquisa constituem-se de estudantes e profissionais atuantes em Secretariado Executivo, no Brasil.

Para a definição e relevância da amostra, utilizou-se a amostra não probabilista obtida por meio da determinação de critérios de inclusão, que nem todos os sujeitos do universo possuem, consequentemente, há uma limitação na seleção dos participantes da pesquisa. Este mecanismo evita a generalização dos resultados obtidos (BICKMAN; ROG, 1997). Nesta investigação, foram considerados os seguintes critérios para demarcação amostral: ser graduado ou estar cursando Secretariado Executivo, estar atuando na área secretarial, desenvolver atividades de gestão e estar acessível à pesquisa (acessibilidade).

A amostra foi composta por 100 secretários executivos atuantes nos diversos setores organizacionais, das seguintes regiões brasileiras, distribuídos da seguinte forma: 13 participantes da região Centro-oeste, 42 participantes da região Nordeste, quatro participantes da região Norte, 20 participantes da região Sul e 21 participantes da região Sudeste. Com o intuito de manter, em sigilo, a identidade dos secretários, os participantes foram identificados por "SECRETÁRIO EXECUTIVO" seguido de um número natural que corresponde à ordem dos questionários.

O instrumento de pesquisa utilizado para a coleta de informações foi o questionário, que "é o conjunto de questões sistematicamente articuladas que se destinam a levantar informações escritas por parte dos sujeitos pesquisados, com vistas a conhecer a opinião dos mesmos sobre os assuntos em estudo." (SEVERINO, 2007, p. 125).

O questionário dividiu-se em quatro partes. A primeira parte corresponde às seis questões de múltipla escolha, referentes ao perfil dos 
respondentes. A segunda, corresponde à questão de número sete e é referente aos aspectos da gestão necessários à atuação como facilitador organizacional, de acordo com o grau de frequência. A terceira parte do questionário aborda as competências gerenciais do papel de facilitador. Nesse item, foram questionadas aos abordados as competências gerenciais utilizadas em sua atuação como facilitador para o alcance dos objetivos organizacionais, considerando o grau de frequência. As questões sete e oito possuem as opções "nunca", "frequentemente" e "sempre" para que os participantes assinalassem de acordo com os aspectos e as competências dos itens, respectivamente em cada questão. Por fim, a última parte do questionário refere-se às contribuições do gestor secretarial para o alcance dos objetivos organizacionais, por meio do papel de facilitador.

A distribuição do questionário foi realizada utilizando-se de ferramenta de construção de instrumento de pesquisa, coleta de dados e tabulação geral - programa SurveyMonkey, aplicado de forma on line. Os desafios e limites da utilização dessa ferramenta consistiram na ausência de contato direto com os sujeitos que impossibilita conquistar maior motivação dos
Para a análise dos dados, inicialmente, foi utilizada a estatística descritiva com o intuito de representar e resumir as informações obtidas por meio de tabelas. A técnica utilizada para a parte qualitativa foi a interpretação à luz da teoria estudada, por meio da análise de conteúdo que, conforme Bardin (2009, p. 27) "[...] observa com interesse as tentativas que se fazem no campo alargado da análise de comunicações: lexicometria, enunciação linguística, análise de conversação, documentação e base de dados, etc."

Nessa fase, foram identificadas as categorias fundamentadas nas respostas que tinham maioria de opções assinaladas nas questões objetivas e de argumentos análogos para as perguntas subjetivas. As informações foram organizadas para análise temática a partir codificação dos dados coletados (BARDIN, 2009).

\section{APRESENTAÇÃO E ANÁLISE DOS RESULTADOS}

Inicialmente, a pesquisa visou conhecer o perfil dos participantes, conforme apresentado na Tabela 1.

Tabela 1 - Perfil dos entrevistados

\begin{tabular}{l|l|l|l|l|l}
\hline Idade & 18 a 26 anos 40\% & 27 a 34 anos $44 \%$ & $\begin{array}{l}35 \text { a } 42 \text { anos } \\
14 \%\end{array}$ & $\begin{array}{l}\text { acima de } 42 \text { anos } \\
2 \%\end{array}$ & \\
\hline Sexo & Masculino $11 \%$ & Feminino $89 \%$ & & & \\
\hline Escolaridade & Graduação $74 \%$ & Especialização 23\% & Mestrado 3\% & & $\begin{array}{l}\text { Acima } \\
\text { de } 20 \\
\text { anos } 1 \%\end{array}$ \\
\hline $\begin{array}{l}\text { Tempo de } \\
\text { atuação }\end{array}$ & 1 ano $22 \%$ & 1 a 5 anos $20 \%$ & 5 a 10 anos $20 \%$ & 10 a 20 anos $10 \%$ & \\
\hline $\begin{array}{l}\text { Tipo de } \\
\text { empresa }\end{array}$ & Pública $41 \%$ & Privada $56 \%$ & & & Sul 20\% \\
\hline Região & $\begin{array}{l}\text { Centro Oeste } \\
13 \%\end{array}$ & Nordeste $42 \%$ & Norte 4\% & Sudeste $21 \%$ & \\
\hline
\end{tabular}

Fonte: elaborada pelos autores (2017).

participantes a fim de que forneçam informações mais aprofundadas e confiáveis. 
A maior parte dos investigados é composta por secretárias executivas que têm entre 27 e 34 anos de idade; sexo feminino; graduadas; atuam na área de um a cinco anos; trabalham em empresas privadas; e residem na região Nordeste do Brasil. É importante destacar que outra grande parte dos pesquisados possuem entre 18 e 26 anos; atuam na área de cinco a 10 anos; e trabalham em órgãos públicos.

Em seguida, buscou-se coletar informações acerca das competências gerenciais do papel de facilitador na atuação do gestor secretarial, na visão de profissionais. Nesse intento, foi indagado aos participantes os aspectos de gestão necessários à atuação como facilitador organizacional.

$\mathrm{Na}$ visão dos secretários executivos, o trabalho em equipe, a comunicação interpessoal, a gestão da informação e do conhecimento e as relações interpessoais são aspectos "sempre" necessários ao papel de facilitador. Já a participação nas tomadas de decisões; a administração de conflitos e a liderança, de acordo com a pesquisa, são "frequentemente" necessárias à atuação neste papel. Verifica-se que nenhum dos aspectos da questão foi assinalado pela maioria dos pesquisados como "nunca" necessários à atuação de facilitador, o que demonstra a necessidade do desenvolvimento de todos os aspectos citados para a atuação desse papel, no âmbito organizacional.

Essa visão dos profissionais é coerente com a percepção de Portela e Schumacher (2009) de que, atuando ao lado do poder decisório, o secretário executivo deve ter visão global da empresa, mesclar competências técnicas e comportamentais. Com relação às competências técnicas, Mintzberg (1973) afirma que se referem à habilidade de conhecer a própria atividade, bem como a atividade da equipe e da organização.

Portela e Schumacher (2009) acrescentam que o secretário executivo deve exercitar habilidades de relacionamento e administração de conflitos, trabalhar com foco e acompanhamento de objetivos e metas e principalmente aprimorar, cada vez mais, suas habilidades de comunicação, a fim de que atue como agente facilitador. Segundo os citados autores, a atu- ação do secretário neste papel se revela nas relações que administra, as quais demandam a sua percepção do ambiente, das pessoas e dos códigos, o seu equilíbrio emocional, a sua flexibilidade e a filosofia da organização.

Segundo Portela e Schumacher (2009), esse profissional deve ter a capacidade de influenciar as pessoas da organização a produzirem de forma coerente com a cultura organizacional e se comportar como ponto de referência aos diversos funcionários da organização, servindo de exemplo para os diversos níveis. Assim, as respostas indiciam aspectos dos comprometimentos esperados por profissionais contemporâneos da área estudada.

O trabalho em equipe proporciona possibilidades de engajamento, de espírito coletivo, de cumplicidades e de parcerias que fortalecem a organização nas ações desenvolvidas por suas equipes, ao mesmo tempo em que encoraja as ações dos gerentes, posto que tem, nas parcerias, a legitimação de um fazer coeso, bom para a organização e para os secretários executivos. Do mesmo modo, a participação nas tomadas de decisão e na gestão de conflitos. Feitos em equipe, os resultados serão mais promissores, porquanto refletem a decisão comum do grupo e podem gerar o empoderamento das ações, minimizando conflitos e erros futuros.

De modo igual, os aspectos de comunicação e informação, bem como suas possibilidades de gestão, são mais bem enfrentados quando todos participam e conhecem suas facetas e formas de difusão. Assim, para além do fortalecimento da cultura organizacional, o grupo fortalece a comunicação organizacional. A Tabela 2 apresenta uma síntese dos dados coletados. 
Tabela 2 - Competências do gestor secretarial no papel de facilitador

\begin{tabular}{|c|c|c|c|}
\hline $\begin{array}{l}\text { Competências do facilitador na atuação do } \\
\text { gestor secretarial }\end{array}$ & Sempre & Frequentemente & Nunca \\
\hline Trabalho em equipe & $58 \%$ & $39 \%$ & $3 \%$ \\
\hline Participação na tomada de decisões & $27 \%$ & $60 \%$ & $13 \%$ \\
\hline Administração de conflitos & $33 \%$ & $56 \%$ & $11 \%$ \\
\hline Comunicação interpessoal & $63 \%$ & $37 \%$ & $0 \%$ \\
\hline Liderança & $32 \%$ & $57 \%$ & $11 \%$ \\
\hline Gestão da informação e do conhecimento & $64 \%$ & $33 \%$ & $3 \%$ \\
\hline Relações interpessoais & $65 \%$ & $35 \%$ & $0 \%$ \\
\hline Construção de equipes & Sempre & Frequentemente & Nunca \\
\hline Contribuo na construção de equipes & $35 \%$ & $59 \%$ & $6 \%$ \\
\hline Compartilho a liderança com o grupo & $33 \%$ & $57 \%$ & $10 \%$ \\
\hline Sou bom ouvinte & $59 \%$ & $40 \%$ & $1 \%$ \\
\hline Ao trabalhar em equipe, sou flexível & $30 \%$ & $69 \%$ & $1 \%$ \\
\hline Tomada de decisões & Sempre & Frequentemente & Nunca \\
\hline Contribuo para o processo de tomada de decisões & $30 \%$ & $62 \%$ & $8 \%$ \\
\hline Gerencio informações para a tomada de decisões & $39 \%$ & $54 \%$ & $7 \%$ \\
\hline $\begin{array}{l}\text { Contribuo para a tomada de decisões de forma } \\
\text { participativa }\end{array}$ & $33 \%$ & $56 \%$ & $11 \%$ \\
\hline $\begin{array}{l}\text { Procuro apresentar questões importantes e } \\
\text { pertinentes às decisões }\end{array}$ & $38 \%$ & $51 \%$ & $11 \%$ \\
\hline $\begin{array}{l}\text { Identifico potenciais obstáculos à implementação } \\
\text { das decisões }\end{array}$ & $26 \%$ & $61 \%$ & $11 \%$ \\
\hline Administração de conflitos & Sempre & Frequentemente & Nunca \\
\hline Procuro solucionar situações de conflitos & $45 \%$ & $50 \%$ & $5 \%$ \\
\hline $\begin{array}{l}\text { Mesclo minhas ideias a fim de criar novas } \\
\text { alternativas }\end{array}$ & $33 \%$ & $64 \%$ & $4 \%$ \\
\hline $\begin{array}{l}\text { Apresento soluções criativas a fim de discutir } \\
\text { discrepâncias }\end{array}$ & $24 \%$ & $70 \%$ & $6 \%$ \\
\hline Evito situações desagradáveis & $54 \%$ & $41 \%$ & $5 \%$ \\
\hline $\begin{array}{l}\text { Evito a outra pessoa quando percebo que ela } \\
\text { pretende discutir discordância }\end{array}$ & $14 \%$ & $36 \%$ & $50 \%$ \\
\hline
\end{tabular}

Fonte: elaborada pelos autores (2017).

A pesquisa buscou conhecer as competências gerenciais utilizadas na atuação do secretário executivo como facilitador. Percebe-se que, na competência de construção de equipes, a maior parte dos secretários executivos afirmaram que "sempre" são bons ouvintes e, ao realizar trabalho em equipe, compartilham as informações; enquanto "frequentemente" trabalham em equipe, nas reuniões de grupo, compartilham a liderança do grupo e, trabalhando em equipe, são flexíveis quanto às próprias ideias. Esses dados inferem que os secretários executivos conhecem as regras para se trabalhar em grupo e, principalmente, aponta para possibilidades de eles construírem equipes de maneira a alcançar os objetivos organizacionais. Esse resultado corrobora a percepção de Barros et al. (2013) ao considerarem que, como facilitador, o secretário executivo possui, como competência central, a construção de equipes. 
De acordo com Quinn et al. (2003), para que uma equipe seja desenvolvida, é necessário que o líder saiba analisar a sua atuação no trabalho em grupo, identificando seus pontos fortes e fracos. Após a análise, sugere-se que aprimorem ou desenvolvam capacidades importantes ao desenvolvimento de equipes, tais como: identificar divergências e discuti-las; contribuir para reuniões de grupo; preocupar-se com os outros; comprometer-se com as tarefas; dispor-se a ajudar os outros nas tarefas; compartilhar a liderança com o grupo; encorajar os demais a participarem; e colocar as necessidades do grupo à frente das necessidades individuais. Esse resultado corrobora com as considerações de Barros et al. (2013), ao destacarem que uma das principais aptidões desse profissional no papel de facilitador é o desenvolvimento de trabalho em equipe, de modo a contribuir para a organização das atividades organizacionais.

$\mathrm{Na}$ tomada de decisões no papel de facilitador, a maior parte dos secretários executivos afirmou que "frequentemente" utiliza todas as subcompetências e os comportamentos citados na questão. Os secretários executivos participantes da pesquisa frequentemente contribuem para o processo de tomada de decisões; gerenciam informações para a tomada de decisões; contribuem para a tomada de decisões de forma participativa; procuram apresentar questões importantes e pertinentes às decisões e identificam potenciais obstáculos à implementação das decisões. Esses dados demonstram que os secretários executivos da pesquisa desenvolvem, com frequência, a competência da tomada de decisões, embora não pratiquem esse desenvolvimento todos os dias (sempre).

O primeiro tópico dessa competência, segundo Quinn et al. (2003), corresponde à avaliação de reuniões. Para que uma reunião seja eficaz, é necessário que seja agendada com antecedência para que os membros se programem; os membros compreendam os objetivos da reunião, bem como os resultados esperados; cada membro compreenda o que se espera dele e dos demais participantes; seja encerrada no horário agendado; os membros ouçam atenta- mente os outros; os membros se expressem de maneira franca, honesta e objetiva; os consensos a que se chegam sejam explícitos e claros, bem como os conflitos sejam explorados abertamente e administrados de maneira construtiva; atinjam-se os objetivos da reunião; a participação de cada membro contribua para os resultados; e os membros se sintam satisfeitos com a reunião.

Os gerentes devem ter a capacidade necessária para conduzir a reunião, a fim de que atendam a esses requisitos e garantam uma reunião eficaz. Além disso, eles, possuindo poder de decidir compartilhar ou não os problemas com a equipe, devem ter discernimento para escolher a melhor alternativa com relação ao grau de envolvimento dos funcionários no processo decisório. Quinn et al. (2003) afirmam que as vantagens da participação da equipe nas decisões são: diversidade de conhecimentos; leque amplo de valores e perspectivas; maior compromisso dos membros com a implementação da decisão; e facilidade de os membros identificarem por si só potenciais obstáculos à implementação.

$\mathrm{Na}$ competência administração de conflitos - realizada pelo facilitador organizacional - a maior parte dos secretários executivos entrevistados afirmaram que "sempre" evitam situações desagradáveis e "frequentemente" procuram solucionar situações de conflito; mesclam suas ideias a fim de criar novas alternativas para resolver controvérsias e apresentam soluções criativas ao discutir discrepâncias.

A maioria dos pesquisados afirmou "nunca" evitar a outra pessoa quando percebe que ela pretende discutir uma discordância. Esses dados demonstram que os secretários executivos da pesquisa, embora não desenvolvam a competência da administração de conflitos diariamente (sempre), desenvolvem-na com frequência, viabilizando a sua atuação como facilitador organizacional. Quanto ao fato de a maior parte dos respondentes nunca evitar o outro para não discutir discordâncias, demonstra que os secretários executivos pesquisados possuem maturidade e profissionalismo no sentido de administrar conflitos. 
De acordo com Rodrigues et al. (2013), saber administrar os conflitos existentes nas organizações é característica fundamental no ambiente empresarial. Para administrar um conflito, o profissional deve se colocar no lugar do outro, saber escutar, ter controle emocional, saber negociar para que ambos saiam em vantagem e ser ativo na tomada de decisões, mas não impor somente as suas vontades.

Segundo Quinn et al. (2003), existem três estratégias distintas de como lidar com conflitos: estratégias orientadas para soluções, estratégias não-confrontadoras e estratégias de controle. Ambas podem ser utilizadas para a solução de conflitos, de acordo com as situações específicas. No entanto, de modo geral, é recomendável que os conflitos sejam solucionados com foco no problema, a fim de que seja resolvido da maneira mais produtiva, utilizando, portanto, as estratégias orientadas para as soluções.

Essas estratégias são utilizadas pelas pessoas que mesclam as ideias para criar novas alternativas para resolver a controvérsia; sugerem uma solução que combinam uma variedade de pontos de vista; cedem um pouco nas próprias ideias quando o interlocutor também cede; integram vários argumentos numa nova solução, a partir dos pontos levantados numa discussão; preferem chegar a uma conclusão que seja meio a meio; apresentam soluções criativas ao discutir discrepâncias; cedem, se o outro se dispuser a chegar a um meio termo; vão ao encontro do outro no meio do caminho entre as opiniões; sugerem que trabalhem juntos na criação de soluções para as diferenças; procuram aproveitar as ideias do outro para gerar soluções; e oferecem trocas para chegar a uma solução. Essas estratégias focalizam o problema e as soluções são propícias para ambas as partes (QUINN et al., 2003).

Foi questionada aos secretários executivos de que forma eles contribuem para o alcance dos objetivos organizacionais, por meio do papel de facilitador. De acordo com as respostas obtidas, as contribuições desses profissionais aos objetivos organizacionais, no papel de facilitador, acontecem por meio da liderança, pro- atividade, comunicação assertiva, resiliência, tomada de decisões, administração de conflitos, relacionamento interpessoal, trabalho em equipe e gestão da informação e do conhecimento. Vale destacar que houve equilíbrio quanto à maioria dos aspectos citados pelos sujeitos investigados. No entanto, há destaque para a gestão da informação e do conhecimento.

O Secretário Executivo 1 afirmou que contribui para os objetivos organizacionais, no papel de facilitador, sendo gestor de informações; utilizando a resiliência; sendo proativo, dinâmico e efetivo; e buscando equilíbrio emocional próprio, do gestor e da equipe. Em complemento, na visão do Secretário Executivo 5, essa contribuição acontece da seguinte forma:

O meu papel de facilitadora é essencial para que a organização cresça de forma harmoniosa e se estabilize comportamentalmente. Resume-se à liderança e à gestão de conflitos de forma que, assim, tudo seja esclarecido, resolvido e analisado para que não ocorram falhas. É como um ciclo PCDA. ${ }^{1} \mathrm{Ou}$ você gerencia bem todas as etapas ou então uma delas vai prejudicar todo o resto. Não adianta ter ótimas informações e não saber se comunicar. Como não adianta ter as duas coisas de maneira ótima e não saber ouvir. É uma soma de tudo (SECRETÁRIO EXECUTIVO 5).

Como líder, o secretário executivo precisa trabalhar em equipe de maneira produtiva. De acordo com Rodrigues et al. (2013), uma das competências mais necessárias a um bom Profissional em Secretariado Executivo é saber trabalhar em equipe. Além de ajudar no desenvolvimento das atividades, o trabalho conjunto ajuda a aprimorar o convívio social no âmbito da empresa, o que facilita as relações interpessoais desse profissional.

A pesquisa apontou, conforme Tabela 2, que $65 \%$ dos participantes destacaram as relações interpessoais como competência gerencial do secretário executivo. Mintzberg (1973) propõe que essa competência está ligada às habi- 
lidades de entender e aceitar a diversidade das pessoas; entender o processo de motivação e utilizar os princípios de motivação adequados a cada pessoa; entender os princípios da liderança e comunicar com eficiência e eficácia.

É válido destacar também a colocação do Secretário Executivo 15, que afirmou: "Como papel de facilitadora, influencio no processo de tomada de decisões, uma vez que apresento argumentos embasados. Porém, isso não me capacita a tomar decisões próprias, juntamente à diretoria estratégica." Tal assertiva representa o grupo dos secretários executivos que ainda buscam a plena atuação como gestores e tomadores de decisões. Esses profissionais influenciam nas decisões por trabalharem ao lado do poder decisório.

No entanto, as decisões estratégicas fogem à sua atuação. Em contrapartida, o Secretário Executivo 20 expõe: "O meu chefe sempre escuta e pergunta minhas opiniões acerca dos assuntos organizacionais, uma vez que ele reconhece o meu papel de mediadora na empresa e, sendo assim, tenho acesso a um grande número de informações." Quinn et al. (2003), os gerentes aumentam o grau de participação da equipe nas tomadas de decisões à medida que apresenta ideias e pede sugestões; sujeita a decisão tomada a modificações; toma a decisão baseada nas sugestões da equipe; estabelece limites e pede à equipe para tomar a decisão; ou permite que os subordinados ajam dentro de limites determinados pelo superior.

No tocante ao trabalho em equipe, tomadas de decisões e gestão das informações, o Secretário Executivo 35 afirma que contribui para o alcance dos resultados organizacionais, por meio do papel do facilitador, da seguinte forma: "Na maioria das vezes, expondo minhas ideias e opiniões, trabalhando em grupo, elogiando ideias e trabalhos dos meus colegas de trabalho e sempre deixando disponível ao grupo e à organização informações que sejam necessárias a todos!" (SECRETÁRIO EXECUTIVO 35).

Em complemento, destacam-se os secretários executivos que utilizam as habilidades e competências para o trabalho em equipe de modo a atingir a organização como um todo, conforme afirma o Secretário Executivo 40: "Procuro organizar melhor as informações e auxiliar em todos os processos e setores para melhorar o fluxo de trabalho." Neste caso, os resultados organizacionais são viabilizados, uma vez que o profissional desenvolve a competência de trabalhar em equipe, visando à produtividade geral da organização, e não somente do setor em que se atua (D'ELIA; AMORIM; SITA, 2013).

O Secretário Executivo 7 demonstra competências gerenciais do papel de facilitador bem desenvolvidas, pois afirma que contribui para os resultados da organização, neste papel, "[...] justamente no fato de não evitar as discordâncias, mas aprender com as opiniões diversas e experiência de terceiros." O Secretário Executivo 65 expressa:

Contribuo de forma profissional, onde apresento ideias viáveis à empresa, demonstro proatividade, competência, responsabilidade, empatia, e postura profissional, apta para ouvir e discutir, tomar decisões cabíveis e, o principal, trabalho em grupo, onde se alcança novas ideias, objetivos, metas e outros fatos que venha a acrescentar como um facilitador (SECRETÁRIO EXECUTIVO 65).

Percebe-se, em tais colocações, compreensão das competências e dos comportamentos que o gestor secretarial deve desenvolver para agregar valor a si e à organização. Por outro lado, demonstrando postura menos ativa como facilitador, o Secretário Executivo 87 afirma: "Procuro fazer a minha parte nesse processo, mesmo sabendo que depende mais da compreensão das pessoas do que do meu papel de facilitador." Em contraponto à postura passiva do Secretário Executivo 87 como facilitador, o Secretário Executivo 7 expõe:

Trabalho com foco em resultados, busco o aprendizado continuo e procuro absorver o que de melhor extraio da minha equipe. Avalio frequentemente os nossos processos pata evitar repetir erros, potencializar o que foi 
positivo e mudar o que não atendeu as expectativas e estou sempre aberta a ouvir as criticas (SECRETÁRIO EXECUTIVO 7).

Outros profissionais respondentes da pesquisa afirmaram contribuir para o alcance dos objetivos organizacionais, por meio do papel de facilitador, de maneira distinta aos secretários executivos anteriores, apontando contribuições por meio de aspectos e competências não considerados por Quinn et al. (2003) como inerentes ao papel de facilitador. Por exemplo, o Secretário Executivo 11 afirmou: "contribuo agindo de acordo com a minha ética profissional." O Secretário Executivo 23 expôs: "contribuo fazendo a assessoria com qualidade e eficiência, pois sou a principal fonte para a diretoria ter eficiência em seu trabalho." O Secretário Executivo 13 afirmou que contribui "vestindo a camisa da empresa". O Secretário Executivo 14 aponta que se mantém atento e se envolve nos processos da chefia, enquanto o Secretário Executivo 38 afirma que somente contribui quando possui domínio sobre o assunto tratado.

Englobando a maior parte das colocações dos secretários executivos investigados, Portela e Schumacher (2009) explicam que o papel de facilitador, exercido pelo secretário executivo, é dividido em quatro facetas indispensáveis à plena atuação deste profissional como tal. Primeiro, o profissional deve atuar como agente de resultados - o secretário executivo deve ter o perfil de gerador de resultados e para conquistá-lo é indispensável que esteja comprometido com a empresa, conhecendo suficientemente o negócio, a cultura, a filosofia, a visão, a missão, os objetivos e as metas organizacionais. Em seguida, deve funcionar como agente da qualidade, visto que, de acordo com Portela e Schumacher (2009, p. 231), "sem a organização do secretário executivo, as demonstrações por ocasião de auditorias para certificações ficam extremamente dificultadas."

O secretário executivo deve ser um agente de mudanças, priorizando o aprendizado, quanto às constantes mudanças empresariais, uma vez que deve ser o primeiro funcionário da organização a assimilar e a aceitar qualquer alteração provinda dos níveis decisórios, para que atue como multiplicador da conscientização dos benefícios que tais transformações proporcionarão à empresa. E, finalmente, o profissional deve atuar como agente facilitador no processo de comunicação corporativa. Segundo Portela e Schumacher (2009), esse profissional deve minimizar os ruídos da comunicação com clientes internos e externos para que os processos decisórios e os resultados empresariais não sofram impactos negativos.

D'elia, Amorim e Sita (2013, p. 120) complementam que para a ascendência do secretário executivo, em relação aos órgãos decisórios da empresa, são necessários: "o conhecimento da estrutura organizacional da empresa, desenvolvimento da habilidade de comunicação interpessoal e tomada de decisões acertadas com calma e bom-senso." Para esses autores, outras características importantes que o profissional deve ter são: "dinamismo, facilidade no trato, flexibilidade para as circunstâncias, conhecimento técnico em relação ao ramo negocial, e ainda às multifunções empreendidas" por ele.

\section{CONSIDERAÇÕES FINAIS}

O desenvolvimento dessa investigação possibilitou algumas considerações acerca dos objetivos propostos. Verificou-se que a maior parte dos secretários executivos pesquisados considera que os aspectos de gestão necessários à atuação como facilitador organizacional. Percebeu-se que as competências gerenciais utilizadas na atuação do secretário executivo como facilitador são as três básicas ao papel de facilitador - construção de equipes, tomadas de decisões e administração de conflitos - subdivididas nos comportamentos e nas subcompetências citadas.

Os resultados apontaram que os secretários executivos pesquisados contribuem como facilitadores à organização por meio da liderança, proatividade, comunicação assertiva, resiliência, tomada de decisões, administração de 
conflitos, relacionamento interpessoal, trabalho em equipe e gestão da informação e do conhecimento. Vale ressaltar que a maior parte dos respondentes utiliza mais de um aspecto para contribuir aos objetivos organizacionais, assim como utiliza de maneira mais ativa a gestão da informação e do conhecimento como ferramenta produtiva do papel de facilitador.

Obteve-se resposta à questão norteadora da pesquisa: como ocorre a atuação do secretário executivo como facilitador no âmbito organizacional? O estudo indicou que, como facilitador, a atuação do secretário executivo no âmbito organizacional ocorre por meio do desenvolvimento de importantes competências. Infere-se, portanto, que as competências gerenciais do papel de facilitador na atuação do gestor secretarial, na visão dos profissionais, são percebidas na atuação do secretário como gestor, contribuindo ativamente para o equilíbrio das organizações contemporâneas, crescentemente complexas e instáveis.

Como limitação do trabalho, salienta-se que este estudo descreveu competências gerenciais do gestor secretarial a partir de uma amostra de estudantes e profissionais da área. Consequentemente, impossibilita estender os resultados alcançados a todos sujeitos que atuam como gestores secretariais. Pela relevância desta investigação e tendo em vista a complexidade da gestão secretarial, recomenda-se o desenvolvimento de pesquisas que explorem as evoluções decorrentes da atuação do secretário executivo como facilitador organizacional, no contexto da gestão secretarial.

${ }^{1}$ Planejar, desenvolver, conferir, agir.

\section{THE MANAGEMENT COMPETENCIES OF THE FACILITATOR ROLE IN THE OPERATION OF THE SECRETARY MANAGER}

\section{ABSTRACT}

The executive secretary, acting alongside the corporate leadership, contributes directly to the achievement of organizational results. $\mathrm{He}$ exerts diverse roles and, on account of that, he needs to permanently develop the managerial skills necessary for his performance. The present research focuses on the role of facilitator exercised by executive secretaries based on Quinn et. al. (2003), when considering the influence exerted by the manager through managerial competences: team building, participatory decision making, and conflict management. This work aims to investigate the managerial competencies of the role of facilitator in the work of the secretarial manager, in the view of professionals. For that, a quantitative-qualitative and descriptive research was carried out, using as data collection technique the application of a questionnaire with 100 students and professionals working in the Executive Secretariat in Brazil. Data analysis revealed that the role of the organizational facilitator is present in the performance of the secretary as manager, contributing actively to the balance of contemporary organizations.

Keywords: Management skills. Managerial Role of the Facilitator. Secretarial Management.

\section{LAS COMPETENCIAS GESTIONALES DEL PAPEL DE FACILITADOR EN LA ACTUACIÓN DEL GESTOR SECRETARIAL}

\section{RESUMEN}

El secretario ejecutivo contribuye directamente para el alcance de los resultados organizaciona- 
les. Ejerce diversos papeles y, por eso, necesita desarrollar permanentemente las competencias gestacionales necesarias para su actuación. La presente pesquisa aborda el papel de facilitador ejercido por los secretarios ejecutivos fundamentándose en Quinn et al. (2003) al consideraren la influencia ejercida por el gestor a través de las competencias gerenciales: construcción de equipos, proceso decisorio participativo y administración de conflictos. Este trabajo tiene como objetivo investigar las competencias gerenciales del papel de facilitador en la actuación del gestor secretarial, en la visión de profesionales. Para tal, fue realizada una búsqueda cuantitativa-cualitativa y descriptiva, utilizando como técnica de colecta de datos la aplicación de un cuestionario con 100 estudiantes y profesionales actuantes en Secretariado Ejecutivo, en Brasil. El análisis de los datos reveló que el papel de facilitador organizacional está presente en la actuación del secretario como gestor, contribuyendo activamente para el equilibrio de las organizaciones contemporáneas.

Palabras-clave: Competencias gerenciales. Papel Gerencial de Facilitador. Gestión Secretarial.

\section{REFERÊNCIAS}

BARDIN, L. Análise de conteúdo. Lisboa: Edições 70, 2009.

BARROS, C. M. P. et al. As competências gerenciais desenvolvidas pelos secretários executivos. GeSec, São Paulo, v. 4, n. 2, p. 25-47, jul./ dez. 2013. Disponível em: $<$ https://www.revistagesec.org.br/secretariado/article/view/131>. Acesso em: 5 fev. 2018.

BARROS, C. M. P.; BRAGA, M. C.; SILVA, J. S. As competências gerenciais na atuação do Secretário Executivo no nível estratégico. Revista Expectativa, Paraná, n. 1, p. 91-106, 2011. Disponível em: $<$ http://e-revista.unioeste. br/index.php/expectativa/article/view/6096>. Acesso em: 30 nov. 2016.
BARROS, C. M. P.; SILVA, J. S.; FERREIRA, F. D. Gestão secretarial: delineando atividades, funções e competências gerenciais. G $\in$ ECont, Floriano, v. 2, n. 2, p. 149-171, 2015. Disponível em: <http:/www.ojs.ufpi.br/index.php/ gecont/article/view/1626/2637>. Acesso em: 5 fev. 2018.

BECKER, G.; CEOLIN, J. Gestão secretarial: uma nova visão de assessoramento nas organizações. Revista do Secretariado Executivo, Passo Fundo, v. 6, p. 1-15, 2010. Disponível em: $<$ http://www.upf.edu.br/seer/index.php/ser/article/view/2100>. Acesso em: 24 nov. 2014.

BICKMAN, L.; ROG, D. J. Handbook of applied social research methods. Thousand Oaks: Sage, 1997.

BICUDO, M. A. V. Pesquisa qualitativa olhada para além dos seus procedimentos. In: BICUDO, M. A. V. (Org.). Pesquisa qualitativa segundo a visão fenomenológica. São Paulo: Cortez, 2011.

CUSTÓDIO, C. M. P. B.; FERREIRA, F. D.; SILVA, L. V. C. O profissional de Secretariado na gestão pública: um estudo de caso na Faculdade de Medicina da Universidade Federal do Ceará (UFC). Secretariado Executivo em Revista, Passo Fundo, v. 4, 2008. Disponível em: $\quad<$ http://seer.upf.br/index.php/ser/article/ view/1770/1178>. Acesso em: 19 jan. 2018.

D'ELIA, Bete; AMORIM, Magali; SITA, Maurício (Org.). Excelência no Secretariado. São Paulo: Ser Mais, 2013.

FERREIRA, A. B. de H. O minidicionário da língua portuguesa. 5. ed. Rio de Janeiro: Nova Fronteira, 2001.

FLEURY, M.; FLEURY, A. Estratégias empresariais e formação de competências: um quebra-cabeça caleidoscópio da indústria brasileira. São Paulo: Atlas, 2000. 
GASSENFERTH, Walter; MACHADO, Maria Augusta Soares; KRAUSE, Walther. Gestão empresarial em gostas. São Paulo: Cengage Learning, 2012.

LEAL, F. G.; MORAES, M. C. B. Perspectivas da atuação do secretário executivo na gestão da internacionalização da educação superior. Revista de Gestão e Secretariado -GeSec, São Paulo, v. 8, n. 1, p. 138-167, 2017. Disponível em: $\quad<$ https://www.revistagesec.org.br/secretariado/article/view/575/pdf $>$. Acesso em: 29 jan. 2018.

LIMA, T. F.; CANTAROTTI, A. A formação e a construção de competências para a atuação do profissional de Secretariado Executivo: um estudo de caso em uma Empresa Júnior. Revista de Gestão e Secretariado, São Paulo, n. 3, p. 94-122, 2010. Disponível em: <http://revistagesec.org.br/ojs-2.2.4/index.php/secretariado/ article/view/17>. Acesso em: 1 dez. 2016.

MAXIMIANO, Antonio Cesar Amaru. Introdução à administração. São Paulo: Atlas, 2011.

MINAYO, M. C. S. Ciência técnica e arte: o desafio da pesquisa. In: MINAYO, Maria Cecília de Souza (Org.). Pesquisa social: teoria, método e criatividade. 18. ed. Petrópolis: Vozes, 2001. p. 9-31.

MINTZBERG, $\mathrm{H}$. The nature of managerial work. New York: HarperCollinsPublishers, 1973.

NASCIMENTO, E. P. Pesquisa aplicada e interdisciplinaridade: da linguística ao secretariado. In: DURANTE, D. G. (Org.). A pesquisa em secretariado: cenário, perspectivas e desafios. Passo Fundo: Ed. Universidade de Passo Fundo, 2012.

NEVES, J. L. Pesquisa qualitativa: características, usos e possibilidades. Caderno de pesquisas em administração, São Paulo, v. 1, n. 3, p. 1-5, 1996. Disponível em: <http://www.dcoms. unisc.br/portal/upload/com_arquivo/pesquisa_ qualitativa_caracteristicas_usos_e_possibilidades.pdf $>$. Acesso em: 1 dez. 2016.

PAES, R. V. O. et al. Novas formas de atuação do profissional de Secretariado Executivo. Revista de Gestão e Secretariado - GeSec, São Paulo, v. 6, n. 1, p. 99-125, 2015. Disponível em: <https://www.revistagesec.org.br/secretariado/article/view/318>. Acesso em: 19 jan. 2018.

PORTELA, K. C. A.; SCHUMACHER, A. J. Gestão secretarial: o desafio da visão holística. Cuiabá: Adeptus, 2009.

QUINN, R. E. et al. Competências gerenciais: princípios e aplicações. Rio de Janeiro: Elsevier, 2003.

RICHARDSON, R. J. Pesquisa social: métodos e técnicas. 3. ed. São Paulo: Atlas, 1999.

RODRIGUES, M. T. O processo de trabalho da Secretária Executiva. In: CARVALHO, A. P. Talentos brasileiros do Secretariado Executivo. São Paulo: Parma Ltda, 2004.

RODRIGUES, R. R. et al. Análise das habilidades interpessoais desenvolvidas na atuação do secretário executivo. Extensão em ação, Fortaleza, v. 3, n. 2, p. 1-12, 2013. Disponível em: <http://www.revistaprex.ufc.br/index.php/ EXTA/article/view/107/88>. Acesso em: 28 fev. 2018.

RODRIGUES, W. C. Metodologia científica. 2007. Disponível em: <http://pesquisaemeducacaoufrgs.pbworks.com/w/file/ fetch/64878127/Willian\%20Costa\%20Rodrigues metodologia cientifica.pdf $>$. Acesso em: 28 set. 2016.

SANTOS, M. E. S.; MORETTO, C. F. O mercado de trabalho do secretário executivo no contexto da dinâmica produtiva e do emprego recentes no Brasil. Revista do Secretariado 
Executivo, Passo Fundo, n. 7, p. 21-35, 2011. Disponível em: <http://seer.upf.br/index.php/ ser/article/view/2324/1478>. Acesso em: 5 fev. 2017.

SEVERINO, A. J. Metodologia do trabalho científico. 23. ed. São Paulo: Cortez, 2007.

SILVA, J. S.; BARROS, C. M. P.; BARBOSA, M. F. S. Fundamentação da gestão secretarial: um estudo bibliométrico. Revista Gestão e Secretariado - GeSec, São Paulo, v. 3, n. 2, p. 106-126, jul./dez. 2012. Disponível em: $<$ https://www.revistagesec.org.br/secretariado/article/view/114>. Acesso em: 19 jan. 2018.

SILVA, J. S.; BARROS, C. M. P.; CRUZ, R. S. O que se compreende por gestão secretarial: percepção de uma amostra de discentes de secretariado executivo. Revista Gestão em Análise, Fortaleza, v. 5, n. 1, p. 65-77, jan./ jun. 2016. Disponível em: <http://periodicos. unichristus.edu.br/index.php/gestao/article/ view/700/316>. Acesso em: 29 mar. 2017.

VAZ, C. F. M. Gestão contemporânea: as novas realidades e as competências do secretário executivo como agente de resultados. Revista do Secretariado Executivo, Passo Fundo, n. 9, p. 39-50, 2013. Disponível em: <http:/www.perguntaserespostas.com.br/seer/index.php/ser/ article/view/4031/2588>. Acesso em: 24 nov. 2015. 